\title{
NOISE REDUCTION AT THE SHOOTING RANGE BY MEANS OF LEVEL-DEPENDENT HEARING PROTECTORS
}

\author{
Rafał Młyński, Emil Kozłowski \\ Central Institute for Labour Protection - National Research Institute, Warsaw, Poland \\ Department of Vibroacoustic Hazards
}

\begin{abstract}
Background: The aim of the tests was to establish the possibilities of reducing impulse noise by using level-dependent hearing protectors at a shooting range. The tests included 9 models of level-dependent earmuffs and 2 models of level-dependent earplugs They were conducted in the presence of impulse noise generated by 7 types of firearms (pistols, a submachine gun, rifles, a shotgun). Material and Methods: The tests were conducted at an outdoor shooting range, using an acoustic test fixture that meets the requirements of the ANSI/ASA S12.42-2010 standard. Noise parameters were established for the noise reaching the microphones installed in the ear simulators of the acoustic test fixture: uncovered and protected by the tested hearing protectors. Results: All 11 tested level-dependent hearing protectors allow to satisfactorily (below the exposure limit values) reduce the C-weighted peak sound pressure level and A-weighted maximum sound pressure level parameters of noise produced during shots from the 7 types of firearms included in the study. Moreover, in the most unfavorable case, the permissible number of impulses due to the value of the A-weighted noise exposure level normalized to an 8-h working day parameter exceeds 5000 per day. Conclusions: Level-dependent hearing protectors constitute the appropriate means to protect the hearing of people at a shooting range, while maintaining the functionality of these protection devices to transmit speech signals. Med Pr. 2019;70(3):265-73
\end{abstract}

Key words: impulse noise, earplugs, attenuation, earmuffs, noise reduction, level-dependent hearing protectors

Corresponding author: Rafał Młyński, Central Institute for Labour Protection - National Research Institute, Department of Vibroacoustic Hazards, Czerniakowska 16, 00-701 Warsaw, Poland, e-mail: rmlynski@ciop.pl Received: December 20, 2017, accepted: September 27, 2018

\section{INTRODUCTION}

Level-dependent hearing protectors are increasingly used, not only at industrial workplaces, but also in the areas of exposure to acoustic impulses generated by firearms. It should be noted that the use of hearing protectors in the presence of firearms being fired is a necessity resulting from the insufficient effectiveness of other technical means of reducing impulse noise, such as noise suppressors [1].

Level-dependent hearing protectors affect the sound that reaches their users. This is performed by an electronic system, equipped with microphones mounted outside the hearing protector and speakers that reproduce the sound under the hearing protector. This system improves the reception of useful sounds (speech, auditory danger signals) in the absence of noise. There is also the potential danger that, with a large amplification in the acoustic signal reproduction system, the sound reaching the person may cause increased noise exposure. The use of hearing protectors must adequately protect the hearing of their users [2].

In order to be able to determine if the hearing protector provides adequate noise reduction, the parameters of the noise heard at the person's location as well as the noise reduction effectiveness of the hearing protector must be known. The methods for determining the reduction (attenuation) of noise by hearing protectors are divided into 2 categories: subjective (using the response of a person) and objective (measured using a microphone). Due to the relatively high values of the peak sound pressure level and the rapidly chang-

Funding: this paper has been based on the results of a research task carried out within the scope of the fourth stage of the National Programme "Improvement of safety and working conditions" partly supported in 2017-2019 - within the scope of research and development by the Ministry of Science and Higher Education/National Centre for Research and Development (project No. III.N.01, main programme's co-ordinator: Central Institute for Labour Protection - National Research Institute, project manager: Rafał Młyński, Ph.D.). 
ing nature of impulse noise, the authors could not use the subjective real-ear attenuation at threshold (REAT) test method [3-5] to assess the effectiveness of noise reduction by hearing protectors for impulse noise [6]. The technical possibility of measuring impulse noise attenuation is provided by objective methods, based on sound pressure level measurements by using a miniature microphone placed in the ear, under the hearing protector (microphone in real ear - MIRE method) [7] or by using acoustic test fixtures [8].

However, conducting impulse noise attenuation tests on hearing protection requires the use of test signals which are inherently dangerous to hearing. In spite of the use of hearing protectors, exposure to impulse noise may be dangerous to hearing [9]. Therefore, a better and safer solution is the use of devices which reproduce human characteristics, which eliminates the need for human participation in the tests $[10,11]$. These devices are called acoustic test fixtures. They are frequently used in tests where impulse noise with a high peak sound pressure level is present [12-14].

So far, only a few studies have been conducted on the reduction of impulse noise by level-dependent hearing protectors [15-17], therefore we have no test results to compare the properties of different hearing protector models used for this purpose. The aim of the tests presented in this paper was to establish the possibilities of reducing the impulse noise using 11 models of leveldependent hearing protectors at an outdoor shooting range (9 earmuffs and 2 earplugs).

\section{MATERIAL AND METHODS}

\section{Hearing protectors included in the tests}

The tests included 11 different models of level-dependent hearing protectors. Nine of them were earmuffs, while the remaining 2 were earplugs. The list of hearing protectors included in the tests is presented in Table 1. This table also contains the letter designation assigned to each hearing protector for the purpose of this study (used henceforth when test results are presented on charts).

\section{Impulse noise source}

The tests of shooting range noise reduction by hearing protectors were conducted at an outdoor shooting range, in the presence of acoustic impulses generated by 7 types of firearms, popular among law enforcement services, sporting enthusiasts and hunters. A list of the firearms included in the tests and the designations of
Table 1. Level-dependent hearing protectors included in the tests and the designations of individual hearing protectors

\begin{tabular}{lll}
\hline \multicolumn{1}{c}{ Hearing protector } & Designation & \multicolumn{1}{c}{ Type } \\
\hline 3M Peltor ComTac XP & A & earmuffs \\
3M Peltor Tactical XP & B & earmuffs \\
3M Peltor Sportac & C & earmuffs \\
3M Peltor ProTac Shooter & D & earmuffs \\
3M Peltor ProTac Hunter & E & earmuffs \\
MSA left/RIGHT CutOff & F & earmuffs \\
MSA Supreme & G & earmuffs \\
Hellberg Active Secure 2H & I & earmuffs \\
Realhunter Active pro & J & earmuffs \\
3M Peltor LEP-100 EU & L & earplugs \\
Etymotic GunSport Pro GSP-15 & M & earplugs \\
\hline
\end{tabular}

Table 2. Firearms included in the shooting range tests and the designations of individual firearms

\begin{tabular}{lll}
\hline \multicolumn{1}{c}{ Firearm } & \multicolumn{1}{c}{ Designation } & \multicolumn{1}{c}{ Type } \\
\hline Walther P99 & firearm 1 & pistol \\
Glock 17 & firearm 2 & pistol \\
PM-98 Glauberyt & firearm 3 & submachine gun \\
Remington 700 & firearm 4 & rifle \\
Mossberg MMR & firearm 5 & tactical rifle \\
Mossberg 500 & firearm 6 & shotgun \\
AKM & firearm 7 & rifle
\end{tabular}

the firearms used for this study (for presenting its results) are presented in Table 2.

The impulses generated during shots from individual types of firearms included in the tests differ in C-weighted peak sound pressure level $\left(\mathrm{L}_{\text {Cpeak }}\right)$ and duration. These differences may be the reason for the varying degree of attenuation of noise generated by individual firearm types by the hearing protectors [12]. In the case of acoustic impulses generated during shots from firearms at a shooting range, the $\mathrm{C}$ duration is the most representative for determining impulse duration, due to the waveform of this noise type; this particular waveform comprises a series of significant increases and decreases of sound pressure. The definition of $\mathrm{C}$ duration [18] specifies that this is the total time the waveform of the analyzed signal exceeds a value of $-10 \mathrm{~dB}$ in relation to the peak value. Moreover, the peak value is calculated using the absolute value of the analyzed signal. All of the weapons in question generate impuls- 
es which should be considered potentially harmful to hearing. The determined C-weighted peak sound pressure level values and the duration of the sample impulses selected from each firearm type are presented in the Results section.

\section{Experimental set-up}

An acoustic test fixture ("artificial head") was used for conducting noise reduction tests by means of level-dependent hearing protectors at the shooting range, establishing the values of noise parameters potentially reaching the hearing protector user. An image of the measurement system used is shown in Figure 1.

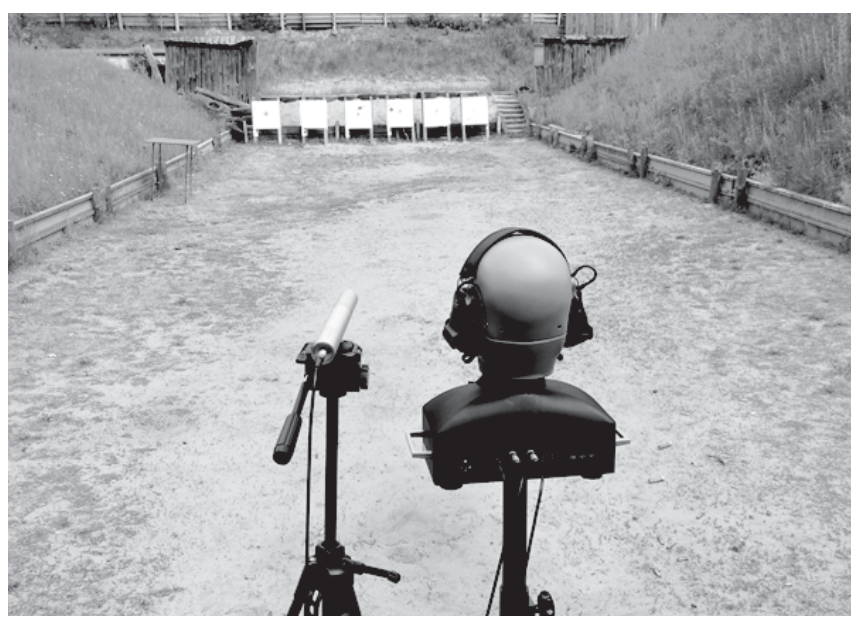

In the foreground: left - a GRAS 67SB transducer used for measuring the properties of acoustic impulses, right - a GRAS 45CB acoustic test fixture to measure the acoustic properties of hearing protectors, with level-dependent earmuffs (test object). The impulse noise is generated by discharging the firearm operated by a shooter (not shown in the photograph).

Figure 1. The measuring system for testing acoustic impulse reduction by level-dependent hearing protectors used during tests at a shooting range

Currently, the most advanced design which enables the modeling of a person's features for the purpose of testing the acoustic properties of hearing protectors is the GRAS 45CB acoustic test fixture (GRAS Sound \& Vibration A/S, Denmark) [19]. This test fixture meets the requirements of the standard on the measurement of the acoustic properties of hearing protectors [20]. The acoustic test fixture models the anatomical shape of the head and ear. Ear simulators and GRAS 40BP microphones were installed in the fixture. Moreover, the fixture elements which could potentially come into contact with the test earplugs or earmuffs were covered with materials with a Shore hardness of 55 (Shore 00), in order to reflect the characteristics of human skin. During the tests, in each measurement situation, a heating system was used in order to maintain the acoustic test fixture at a temperature corresponding to human body temperature. This ensured that the test conditions provided were as close as possible to the conditions in which hearing protectors are used by humans. This is important due to the impact of temperature on the properties of materials used in the manufacture of hearing protectors.

The acoustic impulse parameters were measured using a GRAS 67SB transducer with a GRAS 40DP microphone. Electrical signals from this transducer and from the acoustic test fixture were transmitted to a Brüel \& Kjær 3052-A-030 measurement unit (Brüel \& Kjær, Denmark). For the analysis of measurement data, Brüel \& Kjær PULSE Reflex software was used.

\section{Test performance method}

During the performance of the tests, conditions were achieved in which each of the tested level-dependent hearing protectors was placed on the acoustic test fixture in a manner corresponding to its use by a person. It was therefore attempted to obtain tight adherence between the earmuff cushions and the side surfaces of the test fixture's head, and between the earplugs and the walls of the ear simulator couplers. As it was difficult to obtain the tight adherence of the hearing protectors to the acoustic test fixture surface (requiring considerable experience on the part of the operator), in particular in field conditions, a quality check of the placement of the hearing protector was performed. After each placement of the earmuffs on the acoustic test fixture head or of the earplugs in the test fixture ears, a shot from a starter pistol was fired, while the indications of the measuring instruments were observed. If necessary, the action of placing the hearing protectors was repeated until a satisfactory result was obtained. Adherence checks based on the degree of starter pistol noise transmission under the hearing protector did not guarantee its perfect adherence. For this reason, it was assumed that the tests would be conducted in such a way as to obtain 6 elementary measurement results under a specified hearing protector in every measurement situation.

The elementary measurement situation was understood as measurement conducted during a shot from the specified firearm when the specified hearing protector was placed on the acoustic test fixture. Carrying out 6 measurements enabled the selection of cases in which it was assumed that the adherence of the hearing protector to the acoustic test fixture surface was correct. 
Finally, 3 measurement results of parameters of impulse noise under the specific level-dependent hearing protector were selected (out of 6 measurement results). Thus, the final measurement result under a specific hearing protector for a particular type of firearm was obtained on the basis of measurements carried out in the presence of 3 shots from this firearm. Similarly, 3 shots from the individual type of firearm were taken into consideration when determining parameters of the impulse noise generated by this type of firearm when every hearing protector was tested. Each of the mentioned 3 selected measurement results were averaged. The mean value calculated from the data was expressed in a linear scale i.e., following the conversion of the values expressed in decibels to Pascals.

The tests resulted in obtaining insertion loss representing the noise attenuation by the hearing protector in question. The insertion loss measured using the acoustic test fixture corresponds to sound attenuation measured with human participation [3].

The C-weighted peak sound pressure level parameter, i.e., $\mathrm{L}_{\text {Cpeak }}$ was considered to be the most important parameter concerning impulse noise exposure. Moreover, the remaining 2 noise parameters used in the occupational noise exposure assessment were taken into account: $\mathrm{L}_{\text {Amax }}$ (A-weighted maximum sound pressure level) and $\mathrm{L}_{\mathrm{EX}, 8 \mathrm{~h}}$ (A-weighted noise exposure level normalized to an 8-h working day; otherwise also expressed as daily noise exposure level) [21]. The effectiveness of impulse noise reduction by the hearing protector, due to the $\mathrm{L}_{\mathrm{EX}, 8 \mathrm{~h}}$ value may be assessed by establishing the permissible number of impulses against which the employee using the specified hearing protector will be protected. Therefore, this study has established the permissible number of impulses (PNI) (a single impulse is the result of a single firearm shot), to which the hearing protector user could be exposed, with the assumption of a simultaneous reduction of the $\mathrm{L}_{\text {Cpeak }}$ and $\mathrm{L}_{\text {Amax }}$ parameters below the exposure limit values. The permissible number of impulses was determined on the basis of the formula (1) which takes into account the permissible value of the $\mathrm{L}_{\mathrm{EX}, 8 \mathrm{~h}}$ parameter of $85 \mathrm{~dB}$ [21]:

$$
\mathrm{PNI}=\frac{10^{\frac{85}{10}}}{10^{\frac{\mathrm{L}_{\mathrm{EX}, \mathrm{sh}}}{10}}}
$$

where:

PNI - permissible number of impulses,

$\mathrm{L}_{\mathrm{EX}, \mathrm{gh}}$ - A-weighted noise exposure level normalized

to an 8 -h working day.
It was assumed that the values of the $\mathrm{L}_{\mathrm{EX}, \mathrm{sh}}$ parameter in formula (1) were obtained for every single shot based on formula (2):

$$
\mathrm{L}_{\mathrm{EX}, 8 \mathrm{~h}}=\mathrm{L}_{\mathrm{Aeq}}+10 \lg \left[\frac{\mathrm{T}_{\mathrm{imp}}}{\mathrm{T}_{0}}\right]
$$

where:

$\mathrm{L}_{\text {Aeq }}-\mathrm{A}$-weighted equivalent sound pressure level obtained for 1 shot,

$\mathrm{T}_{\text {imp }}$ - shot duration (time interval used to $\mathrm{L}_{\text {Aeq }}$ calculation), $\mathrm{T}_{0}-$ reference duration $3600 \mathrm{~s}(8 \mathrm{~h})$.

The aforementioned insertion loss is expressed as the difference of the value of the specified noise parameter measured by the acoustic test fixture microphone without the hearing protector and the value of this parameter measured with the hearing protector. In practice it is not possible to simultaneously both listed results, i.e., without and with a hearing protector. In this situation, it is necessary to conduct the measurement using an additional transducer, located next to the acoustic test fixture, which, using the appropriate correction, pursuant to the methodology specified in the reference standard [8], allows to obtain insertion loss values corresponding to the tested hearing protector. Such corrections were, in the past, also used for impulse noise $[14,22]$. Measurement data for establishing this correction were used during additional measurements, conducted simultaneously with 3 microphones (transducer located next to an acoustic test fixture and $2 \mathrm{mi}-$ crophones of the fixture in question) with no hearing protectors on the test fixture.

The results obtained by separate laboratory testing indicated that the presence of the level-dependent system in the case of earmuffs did not impact the attenuation value expressed by the $\mathrm{L}_{\text {Cpeak }}$ parameter, although it was important in the case of earplugs [23].

Therefore, the measurement of the properties of each of the tested earmuffs was conducted with the level-dependent system turned on (the highest amplification in the system was selected). This enabled the most adverse situation, in terms of obtaining sufficient hearing protection for the $\mathrm{L}_{\mathrm{Amax}}$ and $\mathrm{L}_{\mathrm{Aeq}}$ parameters, to be taken into account. In the case of the earplugs, where with the presence of acoustic impulses the role of the level-dependent system was important, the tests were conducted in different modes. The earplugs marked with the letter L: the measurements were conducted with the medium amplification in the level-dependent system (max), average amplification (med) and passive mode (pas); that is, with 
the level-dependent system turned off. In the case of the earplugs marked M, 2 possible modes were used: high amplification $(\max )$ and low amplification (min.). In the case of these earplugs, no measurement in passive mode was conducted, since the earplugs' electronic system could not be turned off.

\section{RESULTS}

The determined C-weighted peak sound pressure level values and the duration of the sample impulses selected from each firearm type are listed in Figure 2. The criterion line of the exposure limit value of the C-weighted peak sound pressure level (135 dB), specified in regulations on hearing protection [21] is also shown.

The values of corrections used for obtaining insertion loss data, mentioned in the Material and Methods section, in the case of the $\mathrm{L}_{\text {Cpeak }}$ parameter, depending on the noise source (firearm type) the values of the corrections, were within the range $3.4-12.3 \mathrm{~dB}$. In the case of the $\mathrm{L}_{\mathrm{Amax}}$ parameter, they were 6.5-11.5 dB. In the

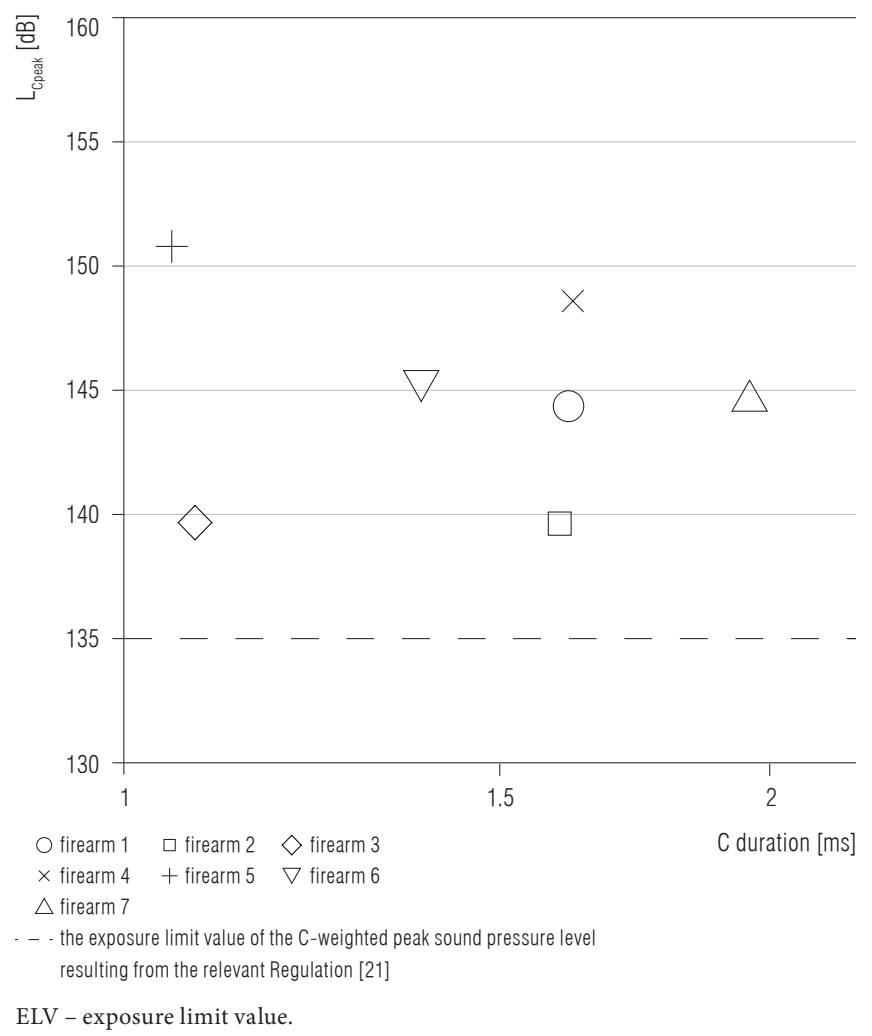

Figure 2. A list of $\mathrm{C}$ duration and $\mathrm{C}$-weighted peak sound pressure level $\left(\mathrm{L}_{\text {Cpeak }}\right)$ values that characterize impulse noise generated during shots from the various types of firearms included in the tests case of the $\mathrm{L}_{\text {Aeq }}$ parameter, the values of the corrections also varied within the range $6.5-11.5 \mathrm{~dB}$.

A list of the values of $\mathrm{L}_{\text {Cpeak }}$ reduction by the tested level-dependent earmuffs is provided in Figure 3, and by the earplugs in Figure 4. In general, it is plausible to state that the lowest values of the $\mathrm{L}_{\text {Cpeak }}$ reduction resulting from the noise attenuation by level-dependent hearing protectors were obtained for the impulses generated by firearm 2 , and then firearm 1 . The highest degree of noise attenuation applies to impulses generated by firearm 5. The difference between the listed highest and lowest $\mathrm{L}_{\text {Cpeak }}$ reduction values, i.e., between the $\mathrm{L}_{\text {Cpeak }}$ reduction established for impulses generated by firearm 2 and impulses generated by firearm 5 are statistically significant. The Wilcoxon test showed $\mathrm{p}=0.0004$ (calculated with the use of Matlab R2017a [version 9.2] with Statistics and Machine Learning Toolbox [MathWorks, Inc., USA]).

The obtained $\mathrm{L}_{\text {Cpeak }}$ reduction values representing the attenuation of noise generated by level-dependent hearing protectors at shooting ranges was used for establishing the range of $\mathrm{L}_{\text {Cpeak }}$ values under the hearing

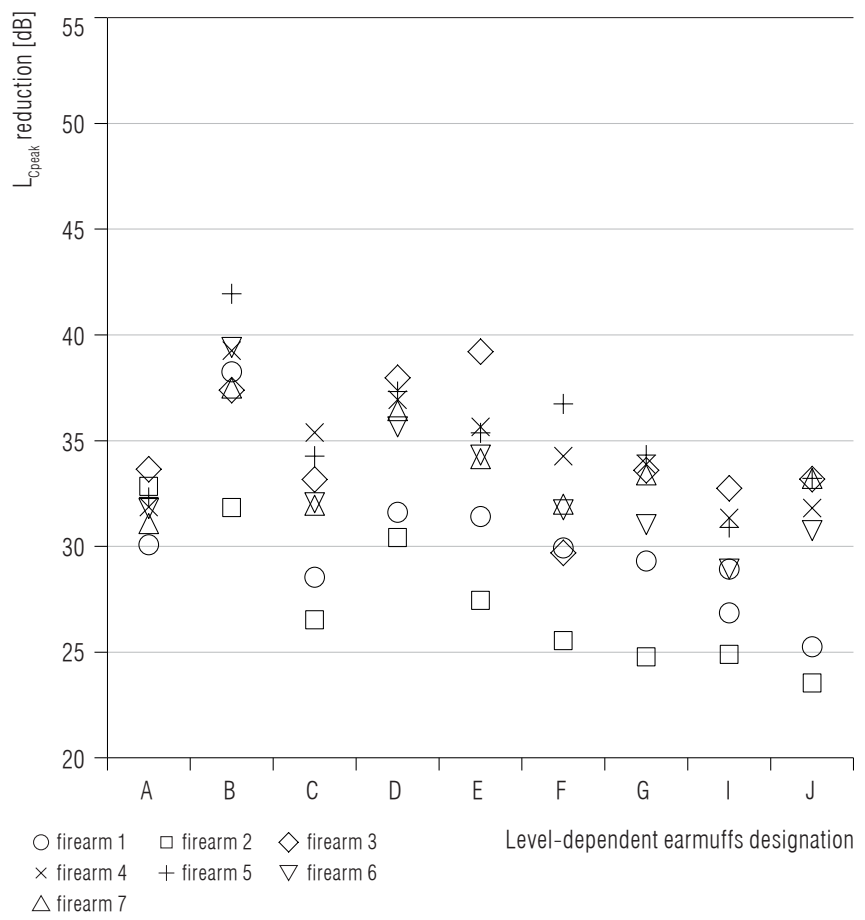

Each presented point on the chart was determined based on measurements carried out in the presence of 3 shots. Hearing protector and firearm designations as in Table 1 and 2.

Figure 3. Reduction of C-weighted peak sound pressure level $\left(\mathrm{L}_{\text {Cpeak }}\right)$ by the tested level-dependent earmuffs 


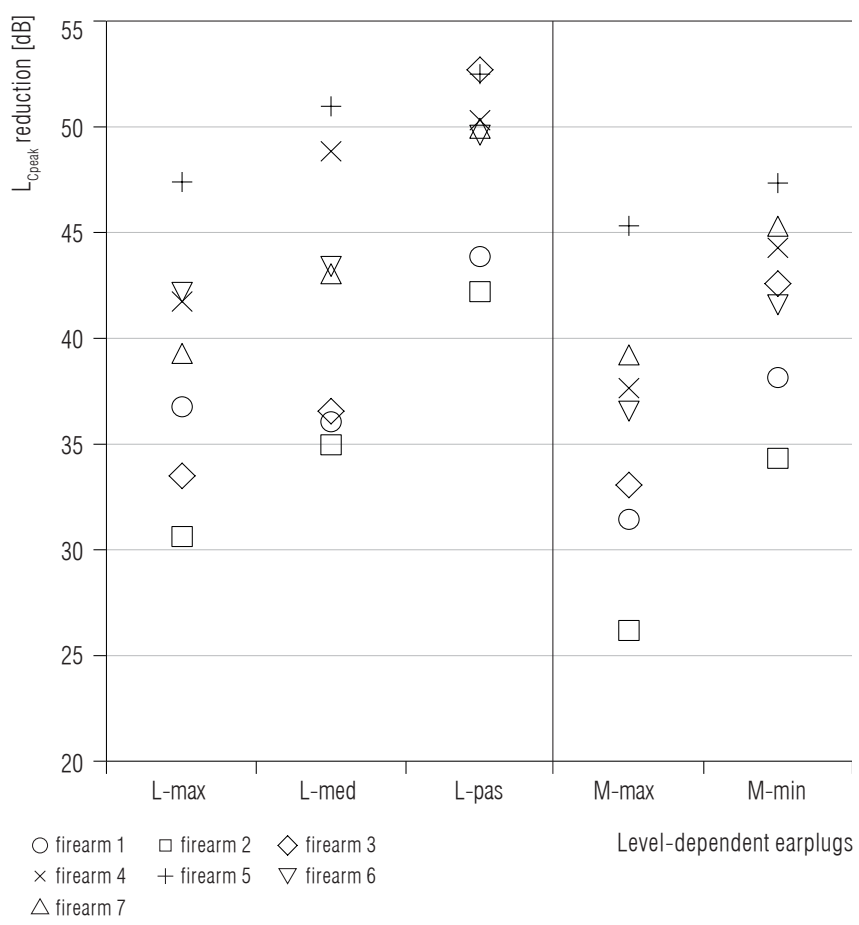

Each presented point on the chart was determined based on measurements carried out in the presence of 3 shots.

max - high amplification in the level-dependent system,

med - average amplification, min. - low amplification, pas - passive mode. Hearing protector and firearm designations as in Table 1 and 2 .

Figure 4. Reduction of $\mathrm{C}$-weighted peak sound pressure level $\left(\mathrm{L}_{\text {Cpeak }}\right)$ by the tested level-dependent earplugs

protectors. It was assumed that outside of the hearing protectors, impulses with the highest $\mathrm{L}_{\text {Cpeak }}$ levels were generated, and were measured during the tests at the shooting range (for each firearm type). Among the values obtained for $\mathrm{L}_{\text {Cpeak }}$ reduction for each of the 7 types of firearms, the lowest $\mathrm{L}_{\text {Cpeak }}$ reduction value and the highest $\mathrm{L}_{\text {Cpeak }}$ reduction value were determined (i.e., in the case of hearing protectors which reduced noise made by a specific type of firearm to the lowest degree). Subsequently, the $\mathrm{L}_{\text {Cpeak }}$ parameter of the noise potentially reaching under the hearing protector was calculated. The results of these activities are shown in Figure 5. It emerged that the range of the $\mathrm{L}_{\text {Cpeak }}$ under the hearing protectors included in the tests, regardless of the hearing protector, was below the exposure limit value. Therefore each of the tested level-dependent hearing protectors sufficiently reduces noise generated by the firearm types included in the test, with regard to the $\mathrm{L}_{\text {Cpeak }}$ parameter.

The highest value of the subsequent parameter: $\mathrm{L}_{\text {Amax }}$ measured in the sound field outside of the hearing pro-

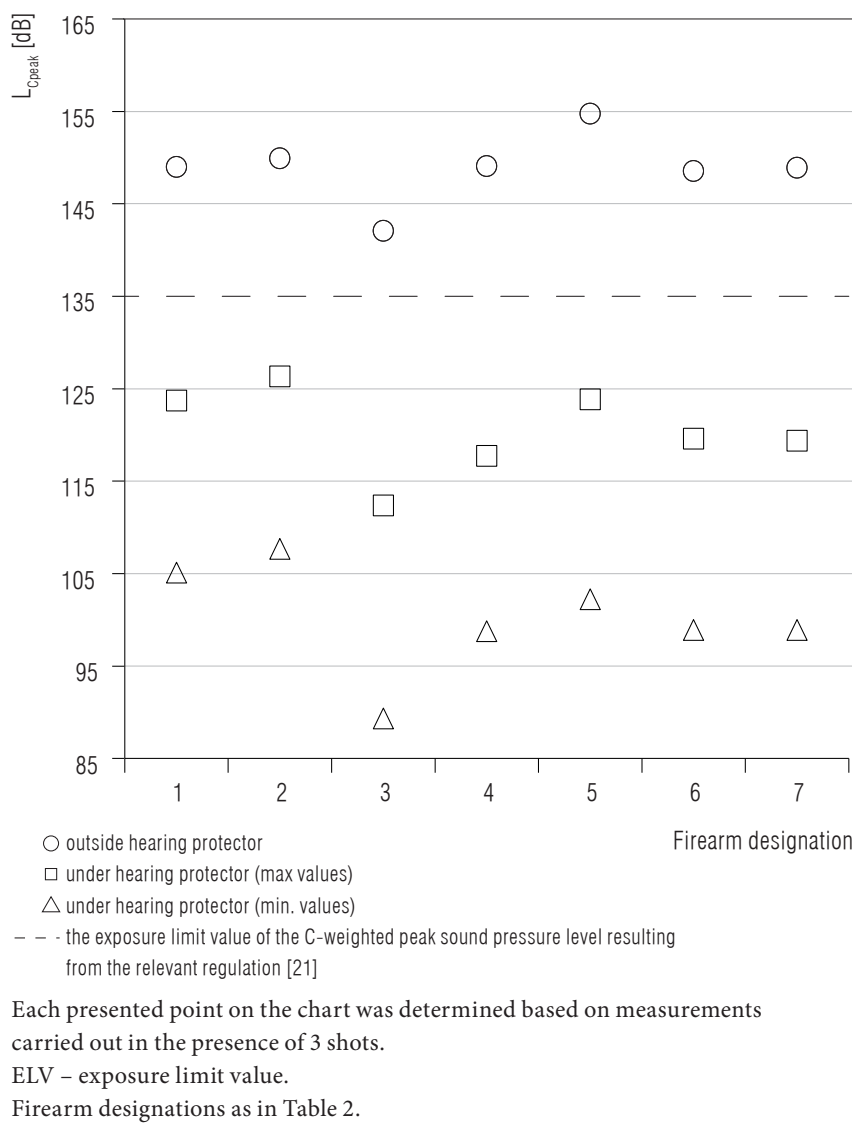

Figure 5. Estimated values of the C-weighted peak sound pressure level $\left(\mathrm{L}_{\text {Cpeak }}\right)$ under the hearing protectors that are best and worst at reducing the impulses generated by various types of firearms

tectors during tests at the shooting range exceeded the exposure limit values of $115 \mathrm{~dB}$ [21] and amounted to $118.1 \mathrm{~dB}$. However, the established values of the $\mathrm{L}_{\mathrm{Amax}}$ parameter reduction are high enough to ensure that in all cases under the analysis, the use of level-dependent hearing protectors resulted in the reduction of the $\mathrm{L}_{\mathrm{Amax}}$ value below $115 \mathrm{~dB}$. The lowest value of the $\mathrm{L}_{\text {Amax }}$ reduction in the case of the shooting range noise amounted to $15.7 \mathrm{~dB}$, which occurred in the case of the level-dependent earplugs marked $\mathrm{M}$, operating in a high amplification mode (max) in the level-dependent system. This means that the reduction of noise generated during shots from the firearms included in the study by all 11 tested level-dependent hearing protectors is sufficient to satisfactorily reduce the $\mathrm{L}_{\text {Amax }}$ parameter even when the generated impulses are characterized by $\mathrm{L}_{\text {Amax }}$ reaching $130 \mathrm{~dB}$.

The calculated permissible number of impulses due to the value of the $\mathrm{L}_{\mathrm{EX}, 8 \mathrm{~h}}$ parameter is given in Figure 6 . It emerged that in the most unfavorable case, this number exceeded 5000 impulses generated during shots. In 


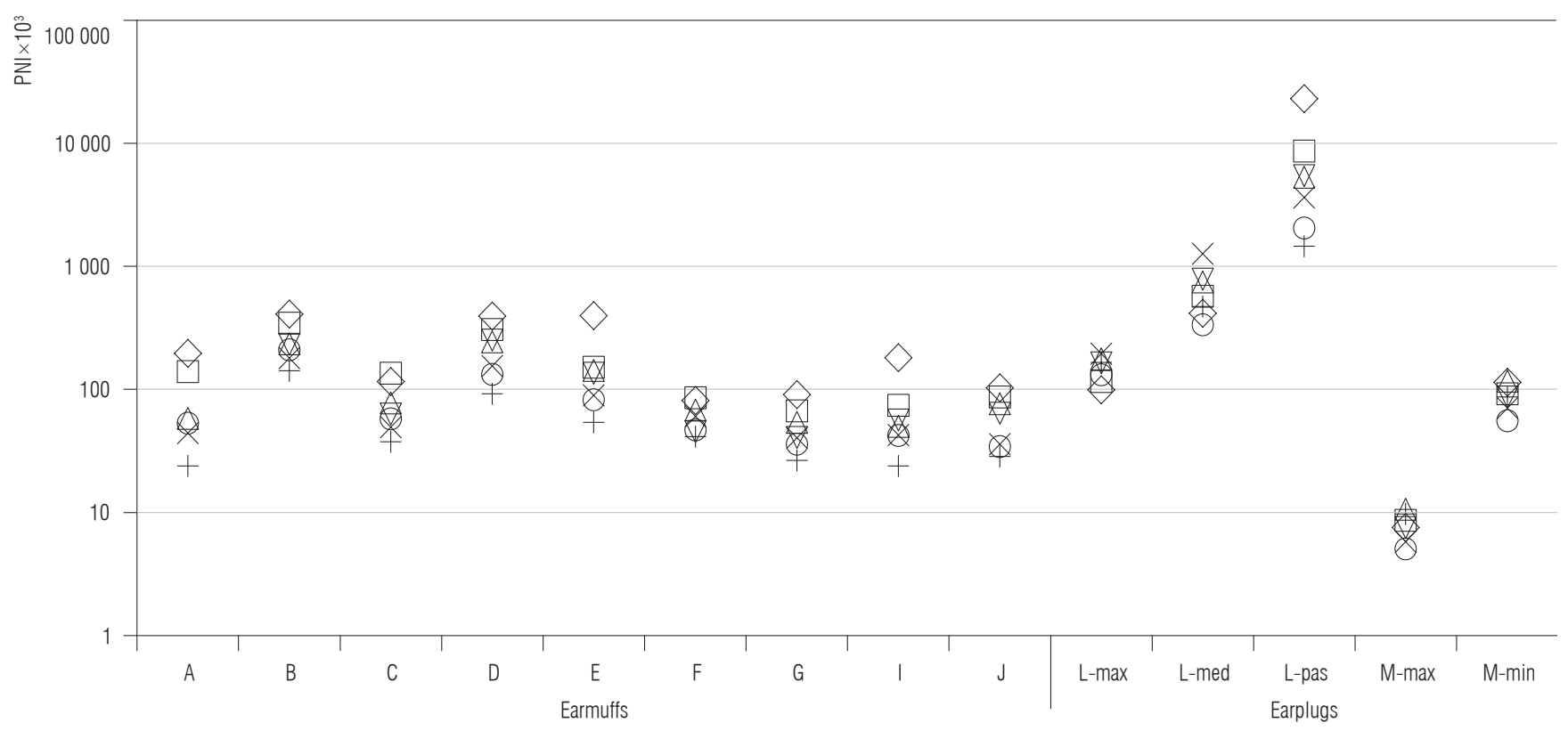

$O$ firearm $1 \square$ firearm $2 \diamond$ firearm $3 \quad \times$ firearm $4 \quad+$ firearm $5 \quad \nabla$ firearm $6 \quad \triangle$ firearm 7

PNI - permissible number of impulses.

Hearing protector and firearm designations as in Table 1 and 2.

Other abbreviations as in Figure 4.

Figure 6. The permissible number of impulses (PNI) resulting from the data on noise exposure, taking into account the use of individual types of level-dependent hearing protectors

practice, during field training exercises the shooter is not exposed to such a large number of impulses. The data specified in Figure 6 may be, however, important for firearm testing employees, where the employee is expected to discharge the weapon a significant number of times, counted in thousands.

\section{DISCUSSION}

The tests conducted during this study enabled the authors to achieve the goal specified in the introduction, which involved obtaining data on the possibilities of reducing the impulse noise at the shooting range by 11 models of level-dependent hearing protectors ( 9 earmuffs and 2 earplugs). The test results obtained through this study are significant since so far there have been no regular data on the reduction of impulse noise generated by level-dependent hearing protectors during shots from firearms.

There is no possibility of a direct comparison of the test results for impulse noise reduction by level-dependent hearing protectors with the results in published studies. Only a study by an American team [17] presents the results of attenuation of noise generated during shots from rifles by $3 \mathrm{M}$ Peltor TacticalPro level-depen- dent earmuffs. These earmuffs are most similar in their design to the 3M Peltor Tactical XP earmuffs included in the tests in this study. The authors of the study in question [17] have specified that the earmuffs they have tested reduce the peak sound pressure level $\left(\mathrm{L}_{\text {peak }}\right)$ generated during a AR-15 rifle shot by the value of $41.2 \mathrm{~dB}$ for impulses with $\mathrm{L}_{\text {peak }}$ of $150 \mathrm{~dB}$. As part of this study, it was tested that the use of $3 \mathrm{M}$ Peltor Tactical XP earmuffs resulted in the reduction of the $\mathrm{L}_{\text {Cpeak }}$ value by $37.5 \mathrm{~dB}$ with impulses with a $\mathrm{L}_{\text {Cpeak }}$ of $146.1 \mathrm{~dB}$, generated by an AKMS $7.62 \times 39$ rifle (firearm 7). Considering the various hearing protector models, types of rifles, peak sound pressure level of the generated impulses and the noise parameter, the result obtained in this study should be seen as consistent with the result presented in the aforementioned study [17].

The efficiency of impulse noise reduction was also assessed using an acoustic test fixture by Buck [15]. The work considered the reduction of impulse noise by level-dependent hearing protectors, however only as an example [15]. It stated that the level-dependent hearing protectors might be treated as passive devices in situations where the sound pressure level value exceeds the level of signal transmission through the electronic system. Whereas in a reverse situation (sound pressure 
level does not exceed the signal transmission level) the hearing protectors may be considered to be devices which transmit sound directly. Therefore, the study did not provide numerical data on noise reduction by level-dependent hearing protectors.

Neither did another study, in which tests were conducted on the reduction of impulse noise by 2 level-dependent hearing protectors [16] provide any data, either, which could be directly compared to the results of this study. This was due to different noise sources and different hearing protector models, as well as differences in established noise parameters.

As shown in the presentation of the results, the lowest values of the reduction of $\mathrm{L}_{\text {Cpeak }}$ resulting from the noise attenuation by level-dependent hearing protectors occur for impulses generated by firearm 2 , and then firearm 1 . The highest degree of noise attenuation applies to impulses generated by firearm 5 . The $\mathrm{C}$ duration is not a universal method of reflecting the time properties of the impulse (due to the waveform's complexity), therefore there is no complete coincidence of the relationship between the example $\mathrm{C}$ durations of the individual weapon types (Figure 2) and the degree of reduction of the noise generated by the individual weapon types, expressed by the $\mathrm{L}_{\text {Cpeak }}$ parameter (Figures 3 and 4 ). It may be noted that the $\mathrm{C}$ duration of the impulse generated by firearm 5 (reduced most significantly) is the shortest whereas the $\mathrm{C}$ duration of the impulses generated by firearm 1 and firearm 2 (reduced least significantly) is longer than in the case of firearm 5 . This observation is consistent with the conclusions of one of the studies published earlier [12], in which it was established that the reduction of impulses by passive hearing protectors was stronger the shorter an impulse was.

Among the hearing protectors included in these studies there are 2 similar models of level-dependent earmuffs, however with different earmuff cup dimensions. These were 3M Peltor ProTac Shooter (D) and 3M Peltor ProTac Hunter (E) earmuffs. The first of these 2 earmuffs was characterized by deeper cups. In the case of impulse noise generated by 6 of the 7 types of firearms, the $\mathrm{L}_{\text {Cpeak }}$ reduction in the case of earmuffs $\mathrm{D}$ (deeper cup) exceeded the values measured in the case of earmuffs $\mathrm{E}$ by $0.2-$ $3 \mathrm{~dB}$ (depending on the firearm type). The only exception was a situation observed during impulses generated during shots from firearm 3 , where the $\mathrm{L}_{\text {Cpeak }}$ reduction in the case of 3M Peltor ProTac Shooter (D) was lower by an average of $1.2 \mathrm{~dB}$ compared to the second of the listed earmuffs. In general, it should be stated that the greater depth of the earmuff cups (and thus the higher mass of earmuffs) favors more significant reduction of the impulse noise generated during firearm shots.

\section{CONCLUSIONS}

This study assessed the effectiveness of impulse noise reduction by level-dependent hearing protectors. The assessment was conducted for 9 earmuffs and 2 earplugs. The tests used the impulse noise generated during shots from 7 types of firearms. The following observations can be formulated based on the tests performed:

1. The range of the $\mathrm{C}$-weighted peak sound pressure level under the hearing protectors included in the tests, regardless of the hearing protector, is below the exposure limit value. Therefore, each of the tested level-dependent hearing protectors sufficiently reduces noise in terms of the $\mathrm{L}_{\text {Cpeak }}$ parameter.

2. All 11 tested level-dependent hearing protectors allow to satisfactorily reduce the $\mathrm{L}_{\mathrm{Amax}}$ parameter of noise produced during shots from the 7 types of firearms included in the study even when the generated impulses are characterized by $\mathrm{L}_{\mathrm{Amax}}$ reaching $130 \mathrm{~dB}$.

3. In the most unfavorable case, the permissible number of impulses against which the hearing protectors provide sufficient protection exceeds 5000. In typical shooting range training conditions, it is not possible for a shooter to discharge as many shots.

In summary, the user of properly worn tested leveldependent hearing protectors, both earmuffs and earplugs, will be sufficiently protected against noise generated at a shooting range during the shots from the 7 types of firearms included in this study. This protection will be provided regardless of the hearing protector mode (level-dependent system or passive hearing protector operation mode).

\section{REFERENCES}

1. Lobarinas E, Scott R, Spankovich C, Le Prell CG. Differential effects of suppressors on hazardous sound pressure levels generated by AR-15 rifles: Considerations for recreational shooters, law enforcement, and the military. Int J Audiol. 2016;55 Suppl 1:59-71, https://doi.org/10.3109/1499202 7.2015.1122241.

2. [Regulation of the Minister of Economy and Labour of $5 \mathrm{Au}-$ gust 2005 on health and safety at work related to exposure to noise or vibration. J Laws 2005, No 157, item 1318]. Polish.

3. ISO 4869-1:1990. Acoustics - Hearing protectors - Part 1: Subjective method for the measurement of sound attenua- 
tion. Geneva: International Organization for Standardization; 1990.

4. EN 13819-2:2002. Hearing protectors - Testing - Part 2: Acoustic test methods. Brussels: European Committee for Standardization; 2002.

5. ANSI/ASA S12.6-2016. Methods for measuring the realear attenuation of hearing protectors. New York: Acoustical Society of America; 2016.

6. Canetto P. Hearing protectors: Topicality and research needs. Int J Occup Saf Ergon. 2009;15(2):141-53, https:// doi.org/10.1080/10803548.2009.11076795.

7. PN-EN ISO 11904-1:2002. Acoustics - Determination of sound immission from sound sources placed close to the ear - Part 1: Technique using a microphone in a real ear (MIRE technique). Geneva: International Organization for Standardization; 2002.

8. ISO 11904-2:2004. Acoustics - Determination of sound immission from sound sources placed close to the ear Part 2: Technique using a manikin. Geneva: International Organization for Standardization; 2004.

9. Job A, Hamery P, De Mezzo S, Fialaire JC, Roux A, Untereiner $\mathrm{M}$, et al. Rifle impulse noise affects middle-ear compliance in soldiers wearing protective earplugs. Int J Audiol. 2016;55(1):30-7, https://doi.org/10.3109/149920 27.2015.1070967.

10. Murphy WJ, Fackler CJ, Berger EH, Shaw PB, Stergar M. Measurement of impulse peak insertion loss from two acoustic test fixtures and four hearing protector conditions with an acoustic shock tube. Noise Health. 2015;7(78): 364-73, https://doi.org/10.4103/1463-1741.165067.

11. Zagadou B, Chan P, Ho K. An Interim LAeq 8 criterion for impulse noise injury. Mil Med. 2016;181(5 Suppl):51-8, https://doi.org/10.7205/MILMED-D-15-00185.

12. Żera J, Młyński R. Attenuation of high-level impulses by earmuffs. J Acoust Soc Am. 2007;122(4):2082-96, https:// doi.org/10.1121/1.2756973.

13. Zera J, Mlynski R, Kozlowski E, Kantor I. Sound levels of gunfire noise during military exercises and the effectiveness of hearing protectors. In: Proceedings of 39th International Congress on Noise Control Engineering 2010, INTER-NOISE 2010; 2010 Jun 13-16; Lisbon, Portugal. Lisbon: Sociedade Portuguesa de Acustica; 2011. p. 3059-67.

14. Lenzuni P, Sangiorgi T, Cerini L. Attenuation of peak sound pressure levels of shooting noise by hearing protective earmuffs. Noise Health. 2012;14(58):91-9.
15. Buck K. Performance of different types of hearing protectors undergoing high-level impulse noise. Int J Occup Saf Ergon. 2009;15(2):227-40, https://doi.org/10.1080/108035 48.2009.11076804.

16. Murphy WJ, Flamme GA, Meinke DK, Sondergaard J, Finan DS, Lankford JE, et al. Measurement of impulse peak insertion loss for four hearing protection devices in field conditions. Int J Audiol. 2012;51 Suppl 1:31-42, https://doi. org/10.3109/14992027.2011.630330.

17. Fackler CJ, Berger EH, Murphy WJ, Stergar ME. Spectral analysis of hearing protector impulsive insertion loss. Int J Audiol. 2017;56 Suppl 1:13-21, https://doi.org/10.1080/ 14992027.2016.1257869.

18. ISO 10843:1997. Acoustics - Methods for the description and physical measurement of single impulses or series of impulses. Geneva: International Organization for Standardization; 1997.

19. Berger EH, Kieper RW, Stergar ME. Performance of new acoustical test fixtures complying with ANSI S12.42-2010, with particular attention to the specification of self insertion loss. In: Proceedings of the 41st International Congress and Exposition on Noise Control Engineering 2012, INTER-NOISE 2012; Aug 19-22; New York, USA. Indianapolis: The Institute of Noise Control Engineering (INCE); 2013. p. 3806-17.

20. ANSI/ASA S12.42-2010. Methods for the measurement of insertion loss of hearing protection devices in continuous or impulsive noise using microphone-in-real-ear or acoustic test fixture procedures. New York: Acoustical Society of America; 2010.

21. [Regulation of the Minister of Family, Labor and Social Policy of 12 June 2018 on the maximum admissible concentrations and intensities of factors harmful to health in the workplace. J Laws 2018, item 1286]. Polish.

22. Młyński R, Kozłowski E. [Assessment of the impulse noise attenuation by earplugs in metalworking processes]. Med Pr. 2014;65(2):197-207, http://doi.org/10.13075/mp.5893. 2014.019. Polish.

23. Młyński R, Kozłowski E. [Reduction of acoustic impulses by level-dependent hearing protectors]. Przegl Mechan. 2017; 12:40-2, https://doi.org/10.15199/148.2017.12.1. Polish.

This work is available in Open Access model and licensed under a Creative Commons Attribution-NonCommercial 3.0 Poland License - http://creativecommons.org/licenses/by-nc/3.0/pl/deed.en. 